\title{
Artificial intelligence in oncology: current applications and future perspectives
}

\author{
Claudio Luchini $\mathbb{D}^{1,2}{ }^{凶}$, Antonio Pea ${ }^{3}$ and Aldo Scarpa $\mathbb{I D}^{1,2}{ }^{凶}$ \\ (c) The Author(s) 2021
}

\begin{abstract}
Artificial intelligence (Al) is concretely reshaping the landscape and horizons of oncology, opening new important opportunities for improving the management of cancer patients. Analysing the Al-based devices that have already obtained the official approval by the Federal Drug Administration (FDA), here we show that cancer diagnostics is the oncology-related area in which Al is already entered with the largest impact into clinical practice. Furthermore, breast, lung and prostate cancers represent the specific cancer types that now are experiencing more advantages from Al-based devices. The future perspectives of Al in oncology are discussed: the creation of multidisciplinary platforms, the comprehension of the importance of all neoplasms, including rare tumours and the continuous support for guaranteeing its growth represent in this time the most important challenges for finalising the 'Alrevolution' in oncology.
\end{abstract}

British Journal of Cancer (2022) 126:4-9; https://doi.org/10.1038/s41416-021-01633-1

\section{INTRODUCTION}

Artificial intelligence (AI) is concretely reshaping our lives and it is time to understand its evolution and achievements to model future development strategies. This is true also for oncology and related fields, where $\mathrm{Al}$ is now opening new important opportunities for improving the management of cancer patients, as will be highlighted in this perspective paper.

In 1950, Alan Turing was the first that conceives the idea of using computers to mimic intelligent behaviour and critical thinking [1]. In 1956, John McCarthy coined the term 'artificial intelligence' as 'the science and engineering of making intelligent machines' [1, 2]. Al began as a simple series of 'if, then rules', and has advanced in subsequent years for encompassing multifaceted and composite algorithms that perform similarly to the human brain [1].

Nowadays, Al represents an emerging and rapidly evolving model that regards different scientific fields, also those devoted to the management of cancer patients [2-5]. It can be seen as a general concept indicating the ability of a machine to learn and recognise patterns and interactions from a sufficient number of representative models, and to use this information for improving the current approach towards the process of decision-making in a specific field [3-5].

In precision oncology, Al is reshaping the existing scenario, aiming at integrating the large amount of data derived from multiomics analyses with current advances in high-performance computing and groundbreaking deep-learning strategies [3]. Notably, the applications of Al are expanding and include new approaches for cancer detection, screening, diagnosis and classification, the characterisation of cancer genomics, the analysis of tumour microenvironment, the assessment of biomarkers with prognostic and predictive purposes and of strategies for follow-up and drug discovery [3-6].

For better understanding current roles and future perspectives of Al, two important terms/definitions, which are strictly associated with Al, should be enlightened: machine learning and deep learning. Machine learning is a general concept indicating the ability of a machine in learning and thus improving patterns and models of analysis, whereas deep learning indicates a machine-learning method that utilises complex and deep networks to finalise a highly predictive performance $[3,4]$. Of note, these two concepts are central also in the Al revolution in the management of cancer patients.

Through a systematic review-based approach, we aim to clarify which are the current applications of Al in oncology-related fields, with a specific focus on already-approved devices. This approach will allow to better understand roles and potentialities of $\mathrm{Al}$ in the management of cancer patients, representing also a reliable point of start for discussing the most important future perspectives of $\mathrm{Al}$ in this field.

\section{METHODS}

The systematic review-based approach adhered to the PRISMA statement preset protocol [7]. For providing a comprehensive portrait of the current situation of the roles played by $\mathrm{Al}$ in the management

\footnotetext{
${ }^{1}$ Department of Diagnostics and Public Health, Section of Pathology, University and Hospital Trust of Verona, 37134 Verona, Italy. ${ }^{2}$ ARC-Net Research Center,

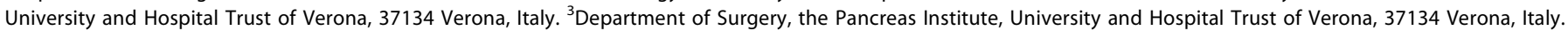
email: claudio.luchini@univr.it; aldo.scarpa@univr.it
} 


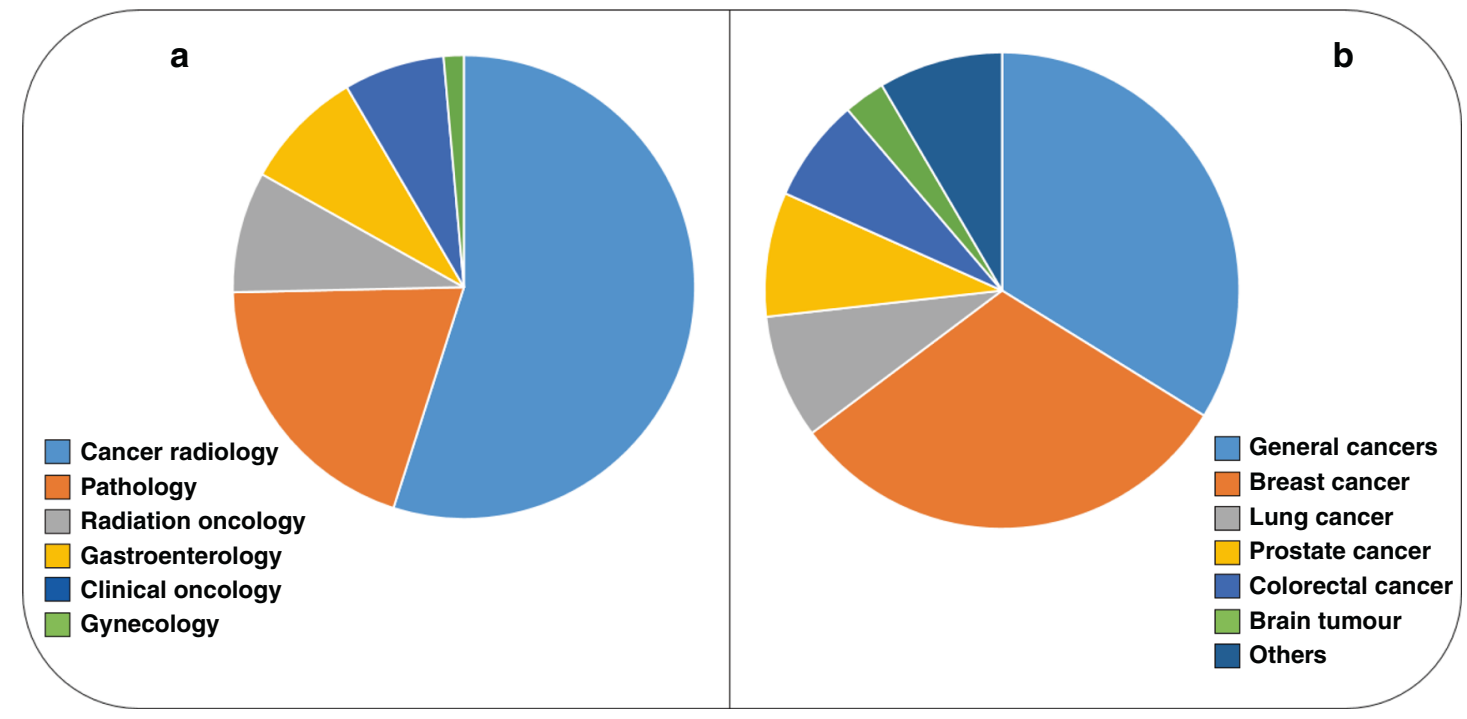

Fig. 1 Current status of Artificial intelligence in oncology and related fields. Summarising representations of the artificial intelligencebased devices, FDA-approved, expressed by oncology-related specialties (a: cancer radiology 54.9\%, pathology $19.7 \%$, radiation oncology $8.5 \%$, gastroenterology $8.5 \%$, clinical oncology $7.0 \%$ and gynaecology $1.4 \%$ ) and by tumour types (b: general cancers $33.8 \%$, breast cancer $31.0 \%$, lung cancer $8.5 \%$, prostate cancer $8.5 \%$, colorectal cancer $7.0 \%$ and brain tumours $2.8 \%$, others: 6 tumour types, $1.4 \%$ each).

of cancer patients, a systematic review was performed, investigating the Al-based devices that have already obtained an official approval for entering into clinical practice in oncology and its related fields. To this aim, two authors (C.L. and A.P.) retrieved all Al-based devices that have obtained the Federal Drug Administration (FDA) approval in oncology-related fields, extracting all potential data by searching FDA official databases (https://www.fda.gov/downloads/medicaldevices/ deviceregulationandguidance/guidancedocuments/ucm514737. pdf; https://www.fda.gov/media/145022/download; https://www. accessdata.fda.gov/scripts/cdrh/cfdocs/cfPMN/denovo.cfm; https:// www.accessdata.fda.gov/scripts/cdrh/cfdocs/cfPMA/pma.cfm; https://www.accessdata.fda.gov/scripts/cdrh/cfdocs/cfpmn/pmn. $\mathrm{cfm}$. Last access for all documents: 05/31/2021. Such data were also integrated with all previous related reviews or commentaries. All data were organised to be separately presented by the specific oncologic areas in the text, as well as in a summary figure (Fig. 1).

\section{RESULTS}

Altogether, the search documented the presence of $71 \mathrm{Al}$-associated or Al-associable devices that have already received an official FDA approval (Table 1), matching data also from previous related reviews $[2,8-10]$. The oncology-related field that counts for the largest number of Al devices is cancer radiology, with the majority of approved devices (54.9\%). It is followed by pathology $(19.7 \%)$, radiation oncology (8.5\%), gastroenterology (8.5\%), clinical oncology (7.0\%) and gynaecology 1 (1.4\%) (Table 1, Fig. 1a). The vast majority of the approved devices $(>80 \%)$ regarded the complex area of cancer diagnostics.

Regarding the different tumour types that can be investigated by adopting such devices, the majority of them has been conceived for being applied to a wide spectrum of solid malignancies (cancer in general, 33.8\%). The specific tumour that counts for the largest number of Al devices is breast cancer (31.0\%), followed by lung and prostate cancer (8.5\% each), colorectal cancer $(7.0 \%)$, brain tumours (2.8\%) and others (6 types, $1.4 \%$ each) (Table 1, Fig. 1b).

\section{DISCUSSION AND FUTURE PERSPECTIVES}

In this paper, a comprehensive overview on current applications of $\mathrm{Al}$ in oncology-related areas is provided, specifically describing the
Al-based devices that have already obtained the official approval to enter into clinical practice. Starting from its birth, Al demonstrated its cross-cutting importance in all scientific branches, showing an impressive growth potential for the future. As highlighted in this study, this growth has interested also oncology and related specialties.

In general, the application of the FDA-approved devices has not been conceived as a substitute of classical analysis/diagnostic workflow, but is intended as an integrative tool, to be used in selected cases, potentially representing the decisive step for improving the management of cancer patients. Currently, in this field, the branches where $\mathrm{Al}$ is gaining a larger impact are represented by the diagnostic areas, which count for the vast majority of the approved devices (>80\%), and in particular radiology and pathology.

Cancer diagnostics classically represents the necessary point of start for designing appropriate therapeutic approaches and clinical management, and its Al-based refining represents a very important achievement. Furthermore, this indicates that future developments of Al should also consider unexplored but pivotal horizons in this landscape, including drug discovery, therapy administration and follow-up strategies. In our opinion, for determining a decisive improvement in the management of cancer patients, indeed, the growth of Al should follow comprehensive and multidisciplinary patterns. This represents one of the most important opportunities provided by Al, which will allow the correct interactions and integration of oncology-related areas on a specific patient, rendering possible the challenging purposes of personalised medicine.

The specific cancer types that now are experiencing more advantages from Al-based devices in clinical practice are first of all breast cancer, lung cancer and prostate cancer. This should be seen as the direct reflection of their higher incidence compared with other tumour types, but in the future, additional tumour types should be taken into account, including rare tumours that still suffer from the lack of standardised approaches. Since Al is based on the collection and analysis of large datasets of cases, however, the improvement in the treatment of rare neoplasms will likely represent a late achievement. Notably, if together considered, rare tumours are one of the most important category in precision oncology [11]. Thus, in our opinion, ongoing strategies 


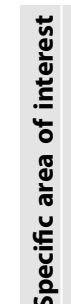

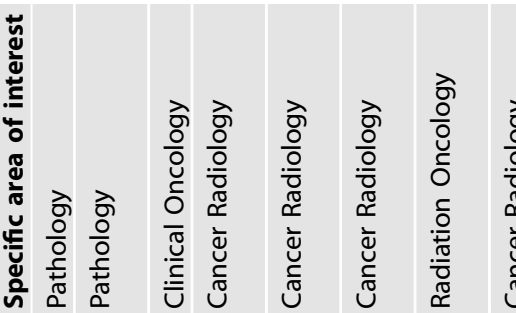

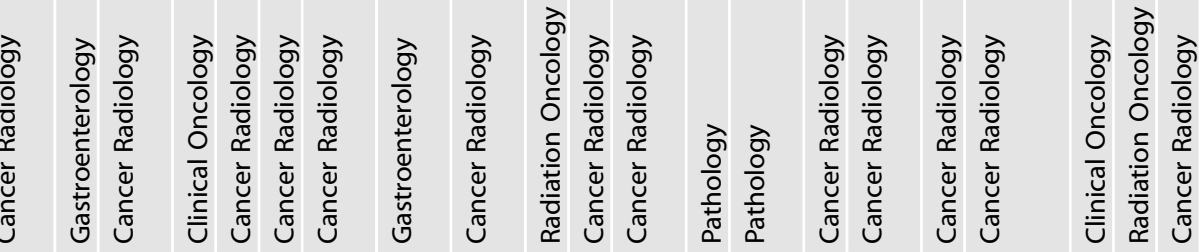

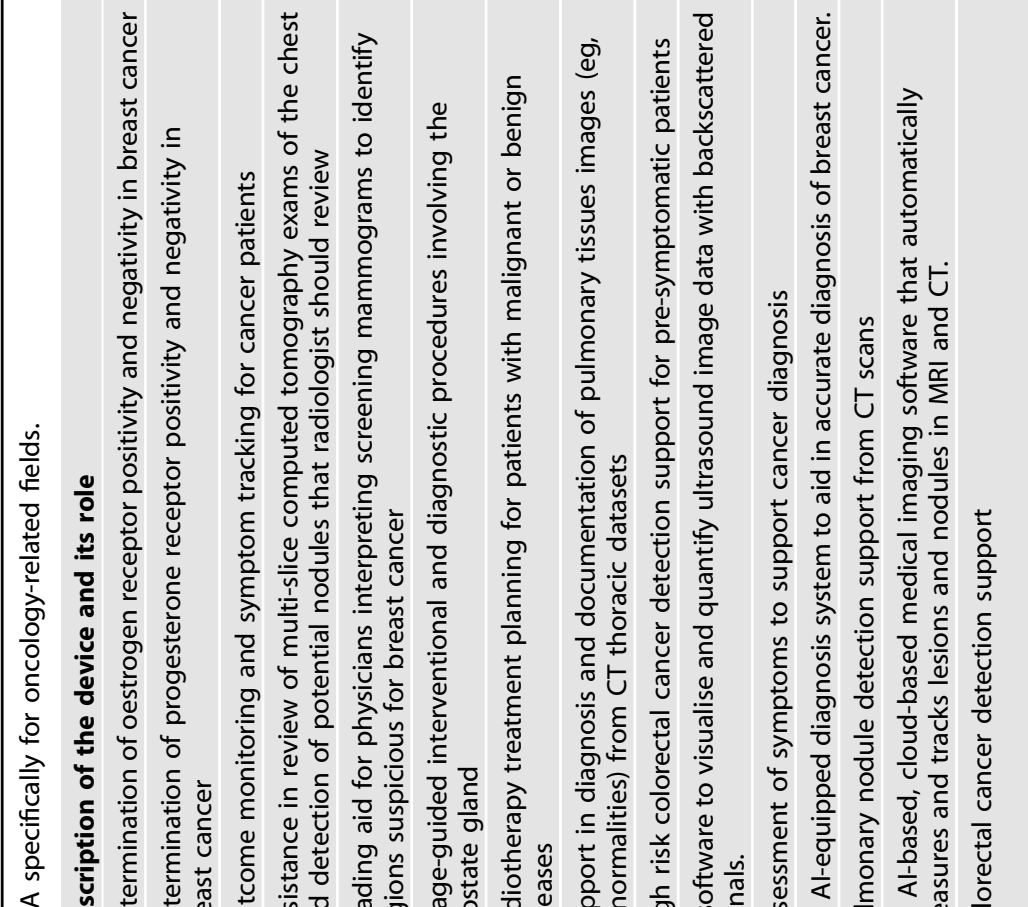

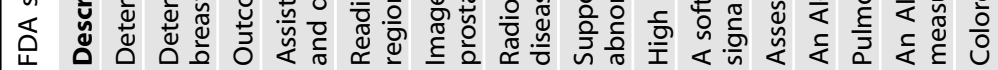

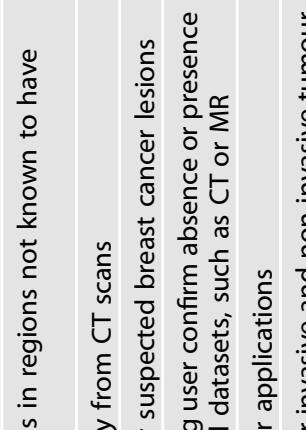

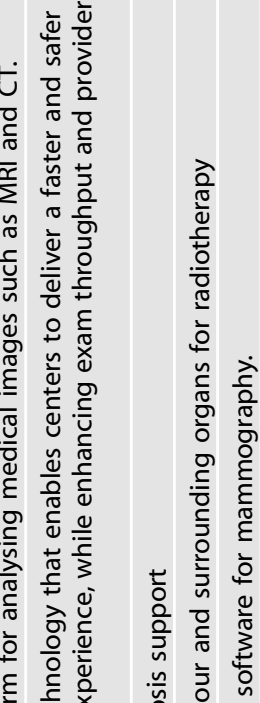

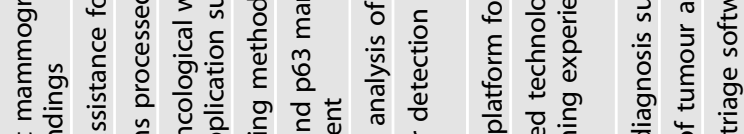

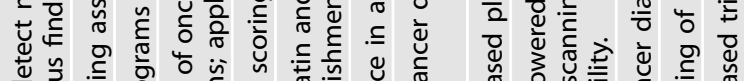

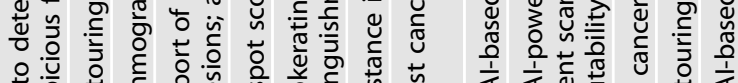

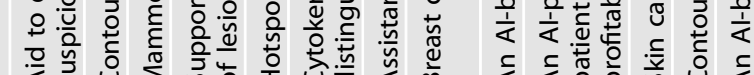
气

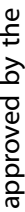

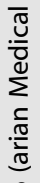

范

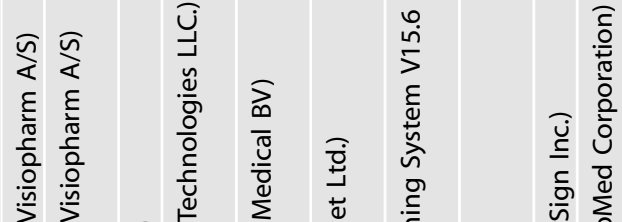

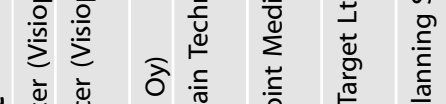

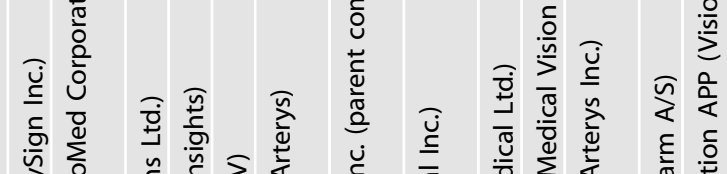

$\frac{\pi}{4}$

高

은

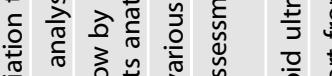

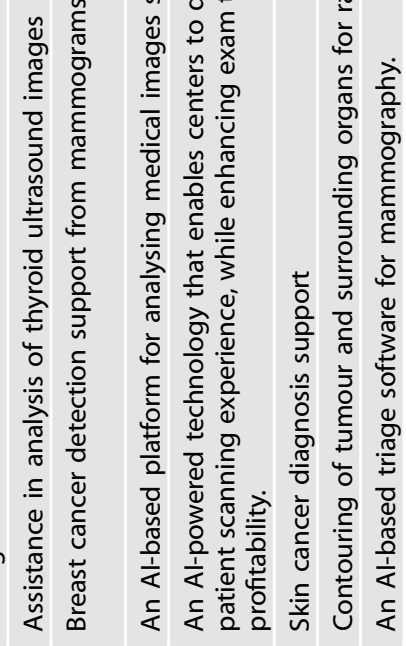

닌

ป

¿ั0

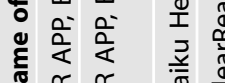

눈 뚠

के

$\frac{8}{2}$

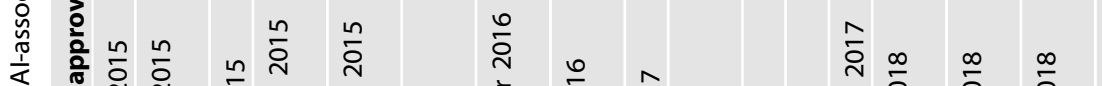

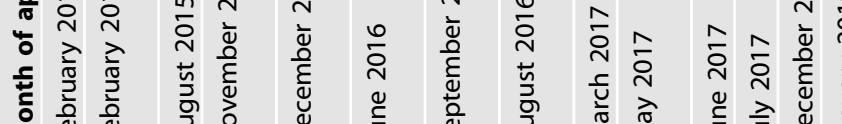
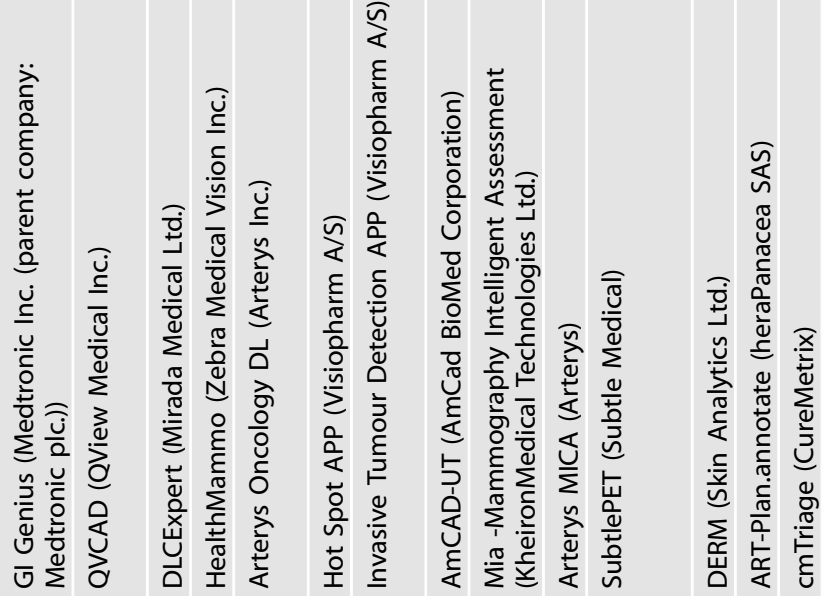

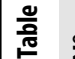

:-

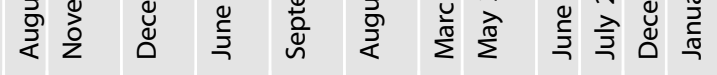

雍

章

$\stackrel{\infty}{\infty}$

$\infty \infty \infty \infty \infty \frac{\infty}{\infty}$

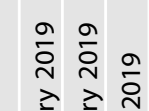

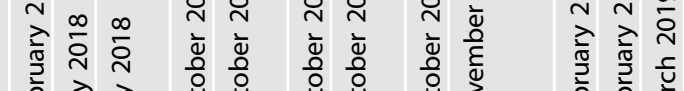

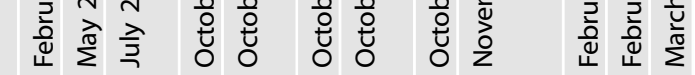

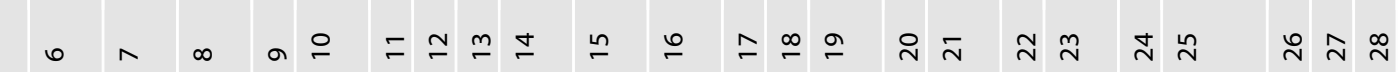


ปั

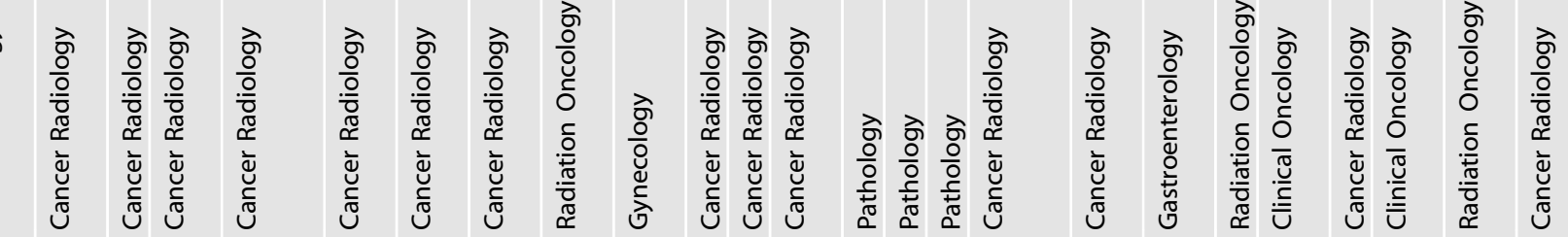

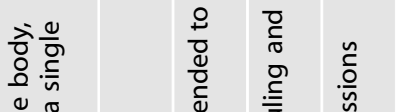
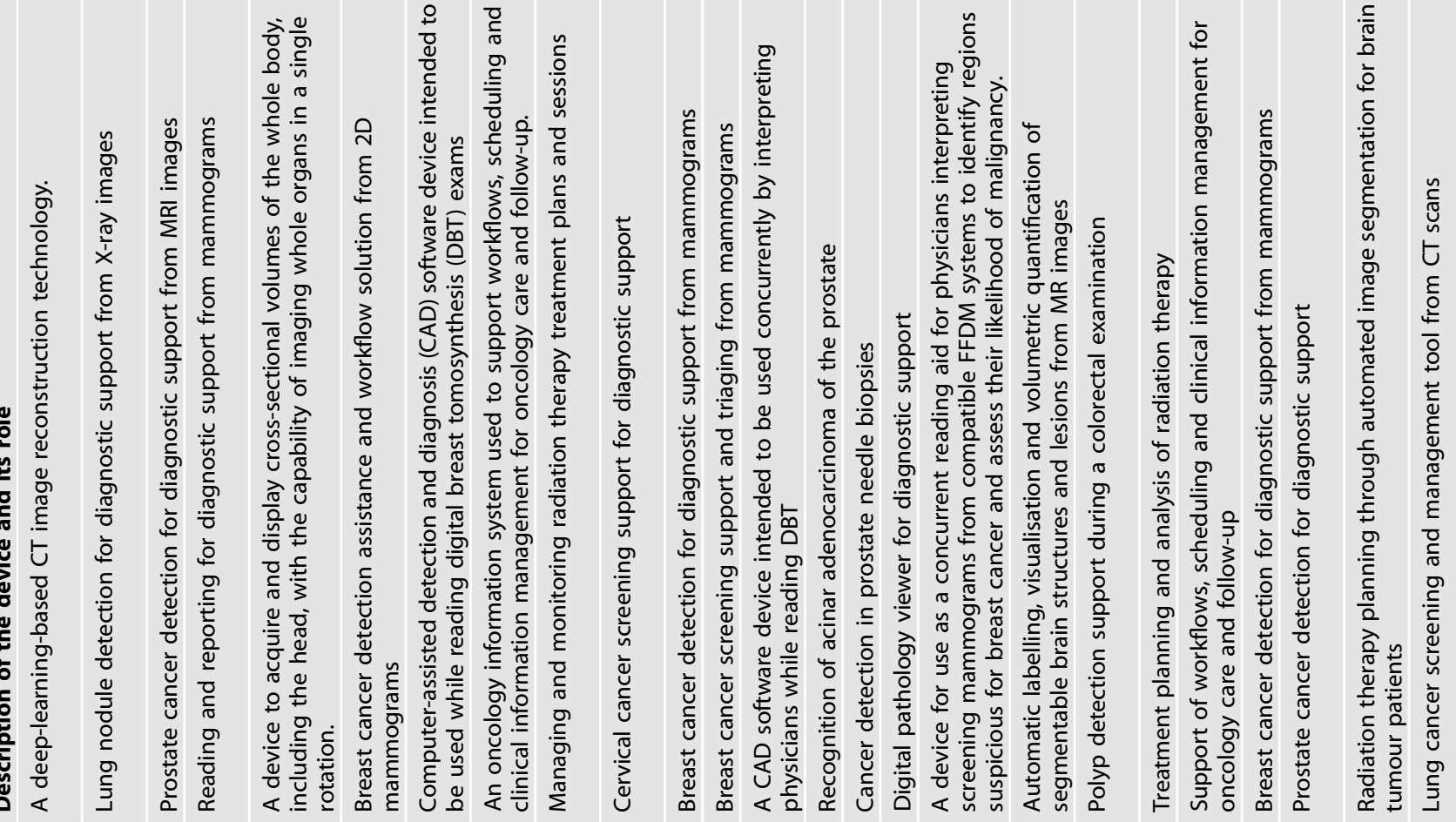

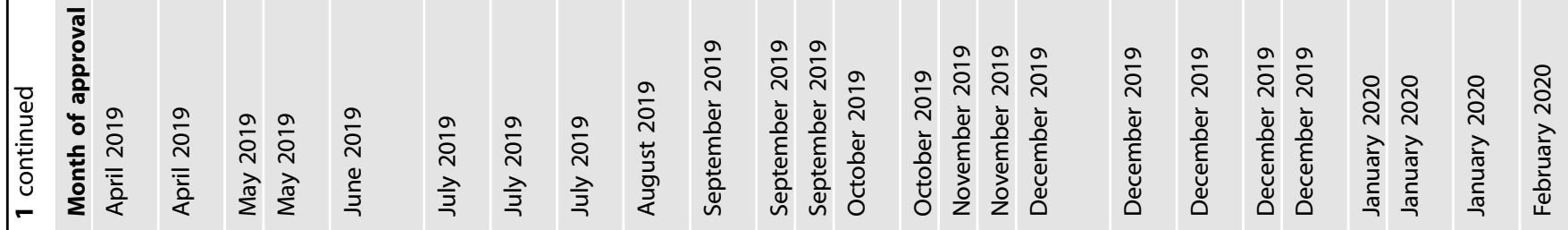
旁
} 


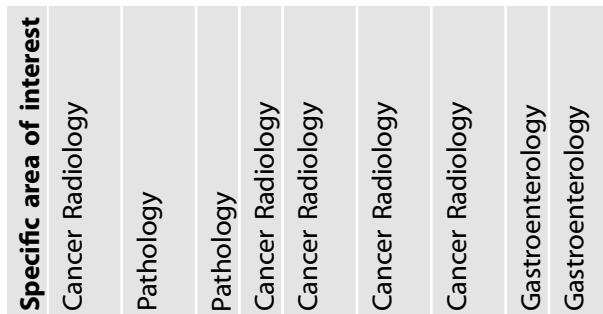

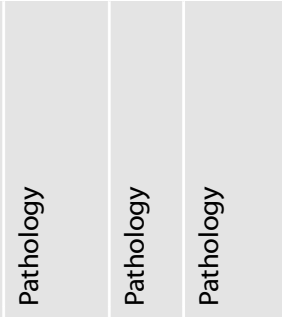

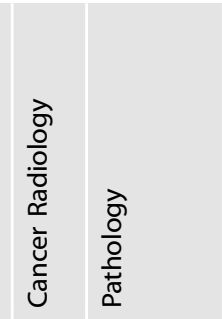
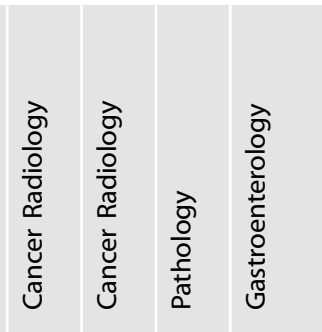

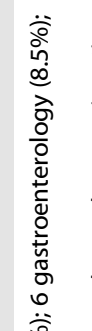

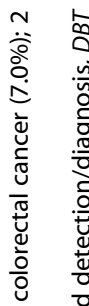

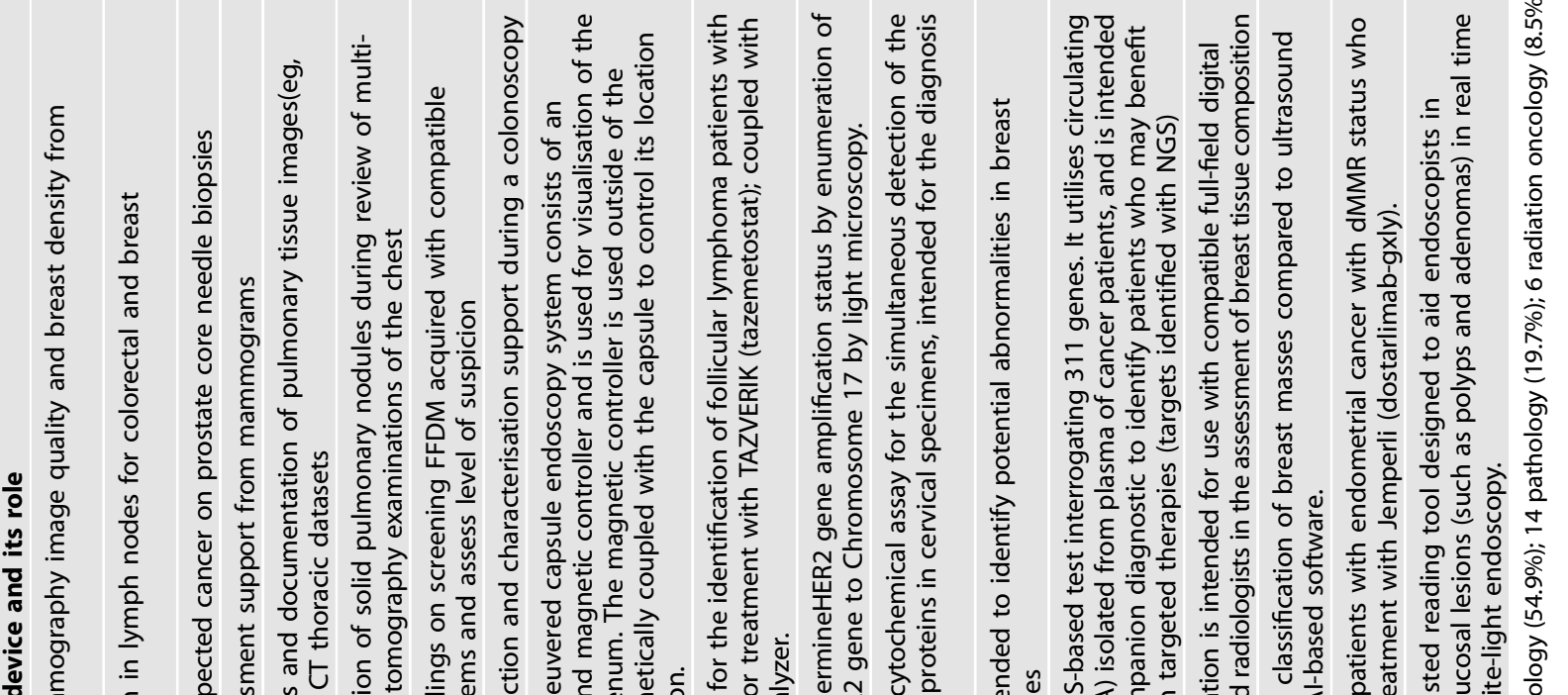

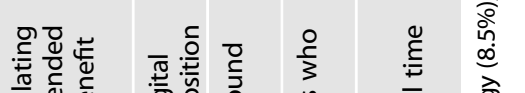

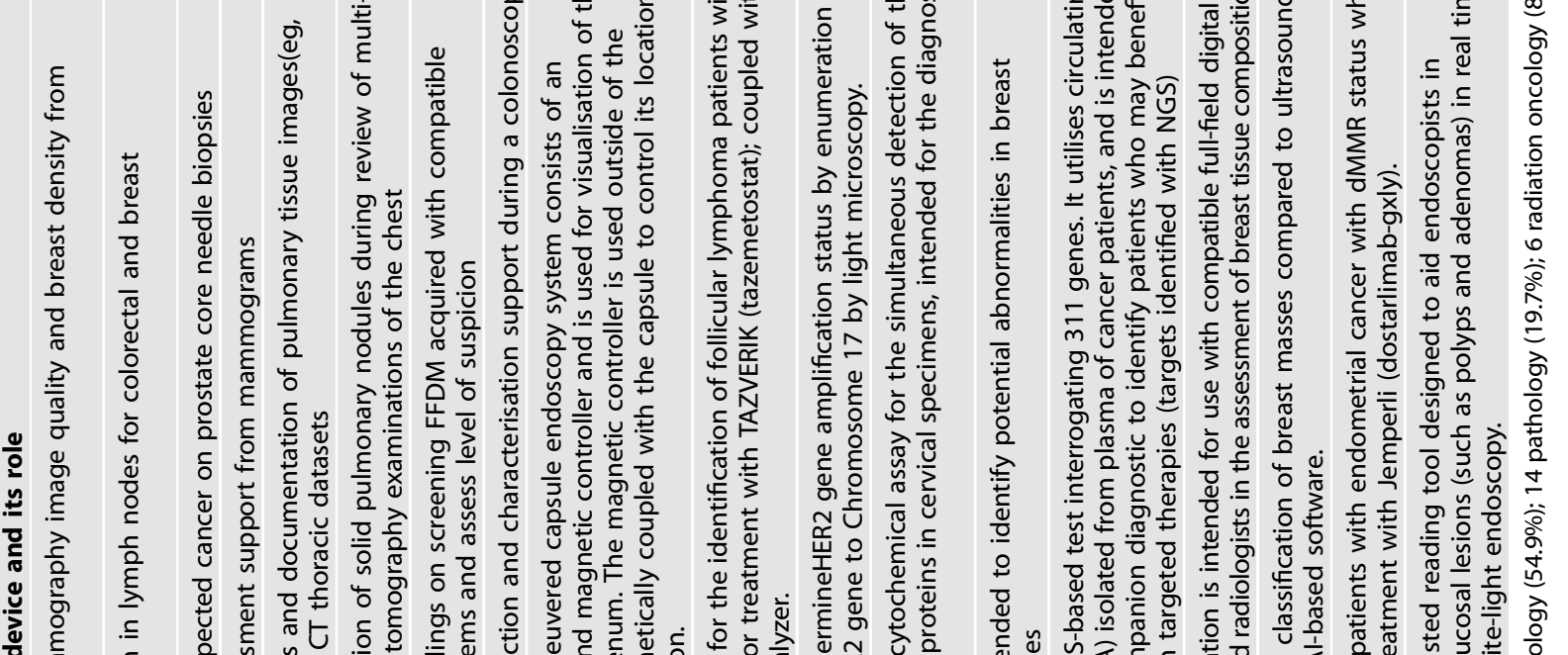

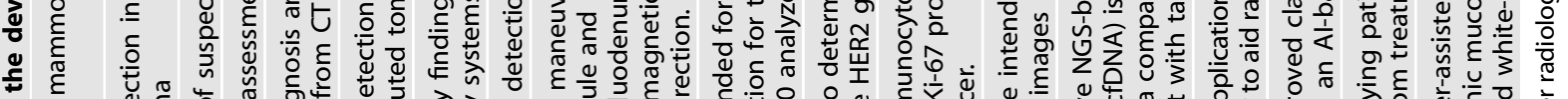
苛

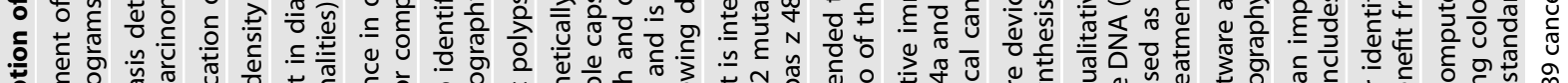

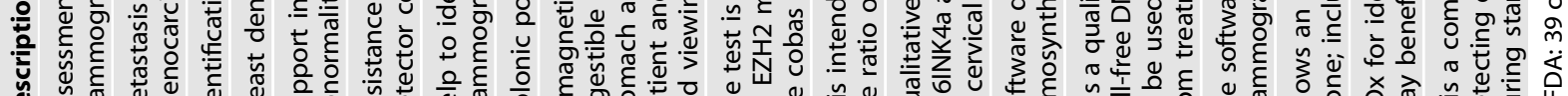

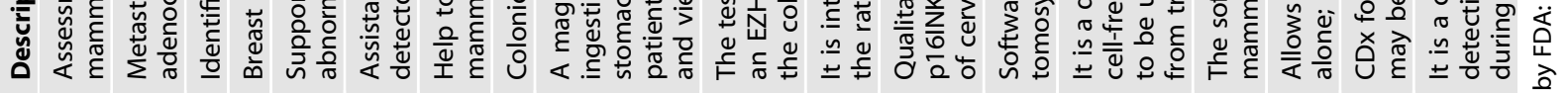

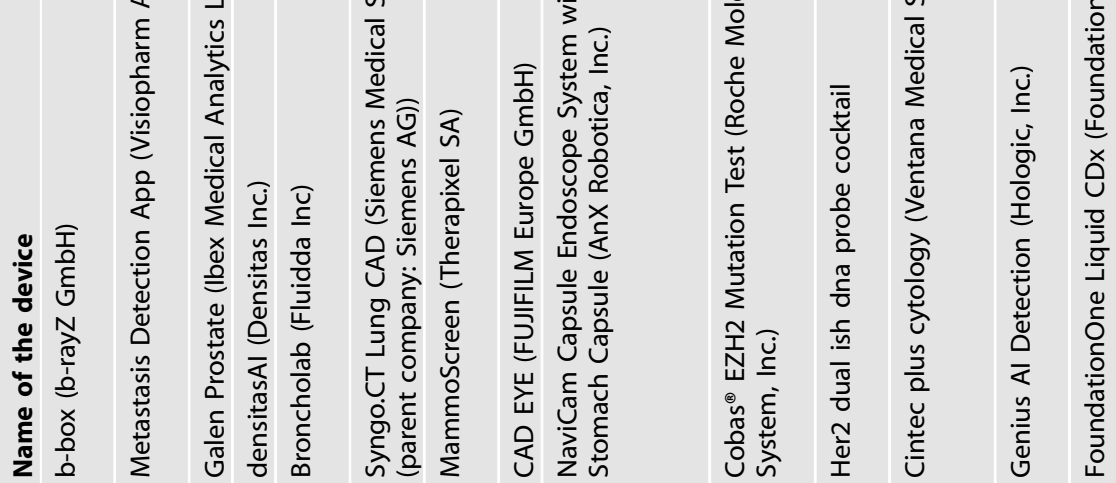

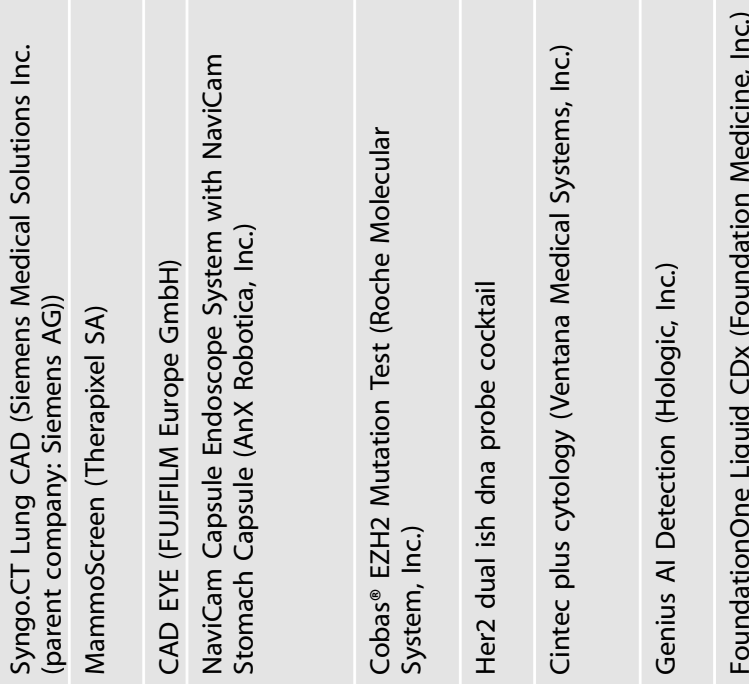

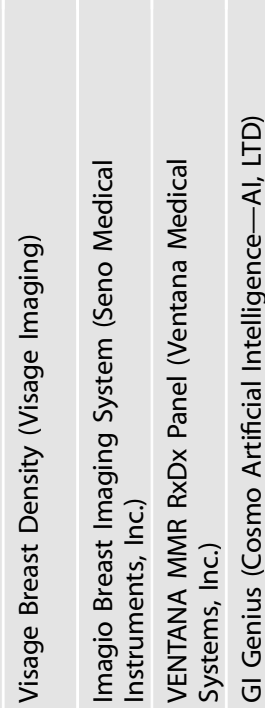

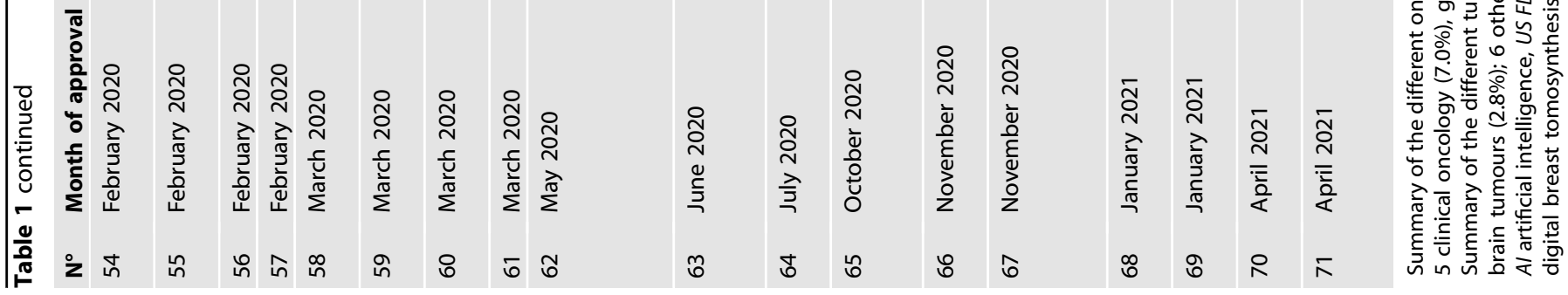


of Al development cannot ignore this tumour group; although the potential benefits seem far away, it is already time to start collecting data on rare neoplasms.

One of the most promising expectancy for $\mathrm{Al}$ is the possibility to integrate different and composite data derived from multi-omics approaches to oncologic patients. The promising tools of $\mathrm{Al}$ could be the only able to manage the big amount of data from different types of analysis, including information derived from DNA and RNA sequencing. Along this line, the recent release of American College of Medical Genetics standards and guidelines for the interpretation of the sequence variants [12] has fostered a new wave of $\mathrm{Al}$ development, with innovative opportunities in precision oncology (https://www.businesswire.com/news/home/20190401005976/en/ Fabric-Genomics-Announces-AI-based-ACMG-Classification-Solutionfor-Genetic-Testing-with-Hereditary-Panels; last access 09/21/2021). In our opinion, however, the lack of ground-truth information derived from protected health- data repositories still represents a bottleneck in evaluating the accuracy of Al applications for clinical decision-making.

Overall considered, $\mathrm{Al}$ is providing a growing impact to all scientific branches, including oncology and its related fields, as highlighted in this study. For designing new development strategies with concrete impacts, the first steps are representing by knowing its historical background and understanding its current achievements. As here highlighted, Al is already entered into the oncologic clinical practice, but continuous and increasing efforts should be warranted to allow Al expressing its entire potential. In our opinion, the creation of multidisciplinary/integrative developmental views, the immediate comprehension of the importance of all neoplasms, including rare tumours and the continuous support for guaranteeing its growth represent in this time the most important challenges for finalising the 'Al-revolution' in oncology.

\section{DATA AVAILABILITY}

All data are available in the paper.

\section{REFERENCES}

1. Kaul V, Enslin S, Gross SA. History of artificial intelligence in medicine. Gastrointest Endosc. 2020;92:807-12

2. Hamamoto R, Suvarna K, Yamada M, Kobayashi K, Shinkai N, Miyake M, et al. Application of artificial intelligence technology in oncology: towards the establishment of precision medicine. Cancers (Basel). 2020;12:3532.

3. Bhinder B, Gilvary C, Madhukar NS, Elemento O. Artificial intelligence in cancer research and precision medicine. Cancer Disco. 2021;11:900-15.

4. Kann BH, Hosny A, Aerts HJWL. Artificial intelligence for clinical oncology. Cancer Cell. 2021;39:916-27.

5. Huynh E, Hosny A, Guthier C, Bitterman DS, Petit SF, Haas-Kogan DA, et al. Artificial intelligence in radiation oncology. Nat Rev Clin Oncol. 2020;17:771-81.

6. Benzekry S. Artificial intelligence and mechanistic modeling for clinical decision making in oncology. Clin Pharmacol Ther. 2020;108:471-86.

7. Liberati A, Altman DG, Tetzlaff J, Mulrow C, Gøtzsche PC, loannidis JP, et al The PRISMA statement for reporting systematic reviews and meta-analyses of studies that evaluate healthcare interventions: explanation and elaboration. BMJ. 2009;339:b2700.

8. Wu E, Wu K, Daneshjou R, Ouyang D, Ho DE, Zou J. How medical Al devices are evaluated: limitations and recommendations from an analysis of FDA approvals. Nat Med. 2021;27:582-4.

9. Muehlematter UJ, Daniore $P$, Vokinger KN. Approval of artificial intelligence and machine learning-based medical devices in the USA and Europe (2015-20): a comparative analysis. Lancet Digit Health 2021;3:e195-e203.
10. Benjamens S, Dhunnoo P, Meskó, B. The state of artificial intelligence-based FDAapproved medical devices and algorithms: an online database. NPJ Digit Med. 2020;3:118

11. Luchini C, Lawlor RT, Milella M, Scarpa A. Molecular tumor boards in clinical practice. Trends Cancer. 2020;6:738-44.

12. Richards S, Aziz N, Bale S, Bick D, Das S, Gastier-Foster J, et al. Standards and guidelines for the interpretation of sequence variants: a joint consensus recommendation of the American College of Medical Genetics and Genomics and the Association for Molecular Pathology. Genet Med. 2015;17:405-24.

\section{ACKNOWLEDGEMENTS}

Not applicable.

\section{AUTHOR CONTRIBUTIONS}

$\mathrm{CL}$ and $\mathrm{AS}$ : study conception and design; $\mathrm{CL}, \mathrm{AP}$ and $\mathrm{AS}$ : systematic review; $\mathrm{CL}$ and $\mathrm{AS}$ : writing, original draft; $\mathrm{CL}, \mathrm{AP}$ and $\mathrm{AS}$ : final editing and approval of the present version.

\section{FUNDING INFORMATION}

This study is supported by Associazione Italiana Ricerca sul Cancro (AIRC $5 \times 1000$ n. 12182); Fondazione Cariverona: Oncology Biobank Project "Antonio Schiavi" (prot. 203885/2017); Fondazione Italiana Malattie Pancreas (FIMP-Ministero Salute J38D19000690001); Italian Ministry of Health (RF CO-2019-12369662: CUP: B39C21000370001).

\section{ETHICS APPROVAL AND CONSENT TO PARTICIPATE}

Not applicable (review-personal perspective).

\section{CONSENT TO PUBLISH}

Not applicable (review-personal perspective).

Competing interests

The authors declare no competing interests.

\section{ADDITIONAL INFORMATION}

Correspondence and requests for materials should be addressed to Claudio Luchini or Aldo Scarpa.

Reprints and permission information is available at http://www.nature.com/ reprints

Publisher's note Springer Nature remains neutral with regard to jurisdictional claims in published maps and institutional affiliations.

\footnotetext{
Open Access This article is licensed under a Creative Commons Attribution 4.0 International License, which permits use, sharing, adaptation, distribution and reproduction in any medium or format, as long as you give appropriate credit to the original author(s) and the source, provide a link to the Creative Commons license, and indicate if changes were made. The images or other third party material in this article are included in the article's Creative Commons license, unless indicated otherwise in a credit line to the material. If material is not included in the article's Creative Commons license and your intended use is not permitted by statutory regulation or exceeds the permitted use, you will need to obtain permission directly from the copyright holder. To view a copy of this license, visit http://creativecommons. org/licenses/by/4.0/.
}

(c) The Author(s) 2021 